\title{
Health care - the secular Leviathan
}

$\mathrm{N}$ eal Blewett and Michael Wooldridge were recent, memorable ministers for health, serving from 1983 to 1990 and 1996 to 2001, respectively. Bill Hayden understood both health and finance and blended these well in developing Medibank while minister for social security from 1972 to 1975 . But the minister who appeared to me to have the greatest effect was Jim Forbes, who was health minister from 1966 to 1971. Forbes was an Adelaide patrician whose doctorate, like that of Neal Blewett, was non-medical. Unlike Blewett, Jim Forbes was a conservative of the most denim-blue hue.

What did Jim Forbes do? In 1968, he appointed a Committee of Enquiry into Health Insurance headed by Justice John Nimmo. Nimmo had cut his teeth in the Depression years as a young criminal lawyer and possessed an excellent insight gained from years at the Bar and on the Bench. He was assisted by an economist who had shifted from engineering into actuarial work as a young man, and for whom Lord Keynes had much admiration, Sir Leslie Melville, as well as Norman McIntosh, a distinguished chartered accountant. Among the many who presented to the Committee, the most influential were two young University of Melbourne academics, John Deeble and Dick Scotton.

The Nimmo Enquiry was limited to work within a voluntary framework. For Deeble and Scotton, its report provided the platform to prosecute the case for a universal medical insurance scheme, with Bill Hayden as their ally.

Nimmo recognised the importance of universality. He also recommended that standard ward accommodation be made available to every person, regardless of means. In differentiating private ward accommodation as a matter of choice, he confirmed retention of the mixed public and private hospital system, with the states having continuing responsibility for public hospitals. ${ }^{1}$ However, what Nimmo did not enshrine was the endless bickering, gaming and cost shifting that have coloured hospital funding ever since.

The initial voluntary element in Nimmo's proposed arrangements sucked in the medical profession, who participated in the establishment of the first list of fees for medical benefit. Doctors contributed "fair and reasonable" fee relativities - in effect defining each item's "common fee for medical benefit". Apart from several notable exceptions, relativities in fees for medical benefit hardly shifted for 30 years.

Australian doctors have always bridled against any suggestion of compulsion, bolstered by the constitutional provision preventing "civil conscription"

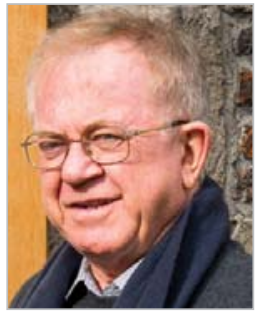

John B Best AO, MDBS, PhD, DSc(Hon) Director of Clinical Training

Murray to the Mountains Intern Training Program, Sydney, NSW.

jbbest@iimetro.com.au doi: 10.5694/mjal3.00079 of medical doctors by the national government. This stance had led to an earlier successful High Court challenge by the British Medical Association, the forerunner of the Australian Medical Association (AMA), of a federal government requirement for signing prescribing paperwork. Conflict between doctors under the AMA banner and supporters of Deeble and Scotton's proposed compulsory scheme was never fully resolved.

First came Medibank, which required a double dissolution of Parliament for its introduction in 1974, and then Medicare in 1983. It soon became so obvious that the Medicare scheme was better than anything else that the conservatives eventually gave up the ideological diatribe around "free markets". Health care does not conform to the rules of the unfettered marketplace. Try the efficiency argument out when a new drug or technique that promises varying degrees of immortality comes onto - or even near — the market. The price tag is exorbitant when considered against the benefit. However, the tide of emotion washes away reality. Clinging to the 100-to-one chance for cure will make the health system as broke as if you tried to use that system on the racecourse.

It is that same emotional tide that can be exploited when there is any suggestion that improvement in the technology should result in reduction in the service price.

Modern living abounds in examples of improvement in technology accompanied by reduction in price. However, using medical equipment is apparently different from the smartphone or the DVD. Medical care is all about "complexity", and it is the dexterity in pressing the switch that is important - and that switch often means "life" or "death" or "good life" quality against "poor life" quality.

When Nimmo produced his report, community expectations of the health care system were considerably lower. Shimmering immortality was not an option. It is not age per se that drives cost, but as has been summarised elsewhere ${ }^{2}$ - as chronic disease progresses, the amount of high-tech health care delivered and the cost associated with this care increase dramatically. Patients with chronic illness in their last 2 years of life account for about $32 \%$ of total Medicare spending in the United States.

Nimmo, Melville and McIntosh, and Deeble and Scotton were remarkable in designing our health financing system by which the government sets a price, and fees and charges can be aligned with this price (or not). Despite all the criticisms, the system has survived. 
However, fuelled by having medical bulk-billing and the right to a public hospital bed, the community often mistakenly expects "universal" to mean "free". Community rating remains an article of faith. Australia thus possesses a universal health scheme whereby the government is the ultimate paymaster - and hence the "fount of all funding" — and the pressures for continued expenditure increasingly displace concerns with cost-effectiveness.

Thomas Hobbes in 1651 published his treatise entitled Leviathan: or the matter, forme and power of a common-wealth ecclesiasticall and civil. Written during the English Civil War, it concerns society and how it might be managed by a strong and united government (the Leviathan), averting war and avoiding anarchy.

The treatise is riddled with allusions to the functioning of the human body - and if Leviathan becomes ill, beware! Hobbes wrote of a disease of a Treasury out of control that resembles what he called pleurisy — "too much abundance" concentrated in too few hands, in the way that Hobbes thought blood to be concentrated in pleurisy with its consequent inflammation and pain. ${ }^{3}$

Australia is now subject to a rampant health Leviathan, where order is missing and anarchy prevails, destroying virtue. Our Leviathan threatens to devour our national wealth. While the "military-industrial complex" has had in the past a Leviathan-like quality in the United States, defence now accounts for but $4 \%$ of the gross domestic product (GDP), while health approaches $18 \%$. When Nimmo wrote his report, health represented about $4 \%$ of Australia's GDP; it now approaches $10 \%$.

The first Nimmo Report came at the right time, but Leviathan had yet to emerge; the next Nimmo will have to face the Leviathan, asking "What price immortality?"

Competing interests: No relevant disclosures.

Provenance: Commissioned; not externally peer reviewed.

1 Commonwealth Committee of Enquiry (Nimmo JA, Chair). Health insurance: report of the Commonwealth Committee of Enquiry. Canberra: Commonwealth Government Printing Office, 1969.

2 Wennberg JE, Fisher ES, Goodman DC, Skinner JS. Chapter 3: How America's best hospitals manage chronic illness. In: Tracking the care of patients with severe chronic illness. The Dartmouth Atlas of Health Care. Lebanon, New Hampshire: Dartmouth Institute for Health Policy and Clinical Practice, Center for Health Policy Research, Dartmouth Medical School, 2008: 39-54.

3 Hobbes T. Chapter XXIX: Of those things that weaken or tend to the dissolution of a commonwealth. In: Leviathan: or the matter, forme and power of a common-wealth ecclesiasticall and civil. London: 1651. http://oregonstate.edu/instruct/phl302/texts/hobbes/leviathan-e. html\#CHAPTERXXIX (accessed Jun 2014).

\section{if \\ Our Leviathan threatens to devour our national wealth}

